\title{
Por uma Sociologia Sistêmica Pós-Colonial da América Latina
}

\author{
Roberto Dutra \\ Professor Associado do Laboratório de Gestão e Políticas Públicas (LGPP), Universidade Estadual do \\ Norte Fluminense Darcy Ribeiro (UENF). Campos dos Goytacazes. Rio de Janeiro, Brasil. \\ E-mail: robertodtj@gmail.com. ORCID: https:/ / orcid.org/0000-0001-7854-1139
}

\section{INTRODUÇÃO}

As aproximações entre os pressupostos epistemológicos e ontológicos da teoria social de Niklas Luhmann e das abordagens pós-coloniais têm sido ressaltadas e desenvolvidas na última década. Os esforços de aproximação focam, entre outras coisas, o ponto de vista pós-fundacionalista, que consiste em recusar a ontologia das identidades, das essências, das substâncias e dos fundamentos últimos em favor de uma perspectiva da diferença, que privilegia as operações cognitivas e práticas de diferenciação, como as responsáveis pela construção da realidade social (Gonçalves, 2013).

No âmbito das teorias pós-coloniais o ponto de vista pós-fundacionalista leva à desconstrução dos discursos hegemônicos e eurocêntricos sobre a modernidade, produzindo uma observação crítica das operações cognitivas e práticas que constroem, num registro essencialista, identidades e casos nacionais baseados nas autocompreensões colonialistas dos países ditos centrais ou desenvolvidos. Nessas teorias, o discurso da modernidade ocidental sobre si mesma (e sobre seu "outro", o "Oriente", a "América Latina", o "resto") é, portanto, o principal objeto de desconstrução, tendo como estímulo histórico-empírico as experiências das regiões pós-coloniais - como América Latina, Ásia e África - com a modernidade (Miglievich-Ribeiro, 2014; Mignolo, 2002; Quijano, 1997). 
Na medida em que a teoria social de Niklas Luhmann parte de pressupostos ontológicos e epistemológicos muito semelhantes, se poderia esperar uma abordagem desconstrutivista também em sua teoria da sociedade moderna, mas até agora a percepção de que a concepção luhmanniana de sociedade mundial é incorrigivelmente eurocêntrica prevalece quase unânime (Souza, 2011). Isso significa que a teoria da sociedade de Luhmann não poderia ser lida e desenvolvida em função do objetivo estratégico de construir uma "sociologia pós-colonial" (Boatc e Costa e, 2010). Dessa forma, esforços de construir uma sociologia da modernidade na América Latina a partir da teoria da sociedade mundial funcionalmente diferenciada de Luhmann, como se tem constatado no caso de Marcelo Neves, estariam condenados a replicar ou atualizar a lógica cognitiva (colonial) que percebe a "modernidade periférica" como "negativa" e deficitária em termos do acesso aos princípios estruturais da modernidade (Souza, 2011).

A crítica pós-colonial apontaria, com toda razão, que as diferenças "modernidade positiva versus modernidade negativa", assim como os déficits de diferenciação funcional atribuídos "ontologicamente" e exclusivamente a determinadas regiões (Dutra, 2016a), constituem uma versão renovada da diferença política pós-colonial, que reifica padrões regionais de sociabilidade como métrica para práticas e discursos de comparação que inferiorizam e periferizam, em diversas dimensões e esferas, outros padrões não convergentes de forma igualmente ontológica e exclusiva.

Essa percepção é justa em face do potencial e da complexidade da teoria de Luhmann? Pode sua teoria da sociedade mundial não ser eurocêntrica? É possível recepcioná-la de um modo em que as diferenças e desigualdades regionais não sejam subsumidas em categorias reificadas e reificadoras, como moderno/atrasado, positivo/negativo, plenitude/déficit?

Apoiando-se em debates mais recentes e menos ortodoxos sobre o tema, defende-se neste artigo a tese de que a teoria da sociedade mundial de Luhmann pode ser recepcionada em favor da crítica ao discurso hegemônico e eurocêntrico sobre a modernidade. E isso sem violar nenhum de seus pressupostos e conceitos fundamentais. $\mathrm{O}$ argumento principal é que as análises de Luhmann sobre os efeitos e paradoxos da diferenciação da sociedade em subsistemas já haviam rompido com o discurso hegemônico sobre a modernidade. E apesar dos elementos 
inegavelmente eurocêntricos, é possível falar em um potencial pós-colonial na teoria dos sistemas, sem, no entanto, recorrer à extrapolação da categoria do "político" e das narrativas de dominação e poder para descrever a variedade global de padrões de sociabilidade moderna e, ao mesmo tempo, sendo capaz de romper com naturalizações das diferenças coloniais à medida que se desenvolve certa sensibilidade teórica e empírica para a dimensão cognitiva da colonialidade que perpassa a ciência e a filosofia sociais modernas.

Sustento que a teoria de Luhmann pode servir de base para uma "sociologia pós-colonial" (Boatc e Costa e, 2010) capaz de combinar a análise da unidade da sociedade mundial com a consideração das diferenças e variedades construídas em seu interior. No entanto, a teoria da sociedade de Luhmann tem um problema grave que precisa ser enfrentado, e para o qual tem demonstrado pouca sensibilidade, o que não é uma decorrência interna da própria teoria: sua descrição da transição à sociedade moderna enxerga somente um processo de diferenciação singular e interno à Europa, desconsiderando, como os pós-coloniais costumam dizer, o papel da "diferença colonial" na constituição da chamada "transição para a modernidade". Para se afirmar como "sociologia pós-colonial" capaz de compreender a globalidade das diferenças regionais, a teoria dos sistemas precisa não apenas investir em estudos sobre a globalização dos sistemas funcionais a partir do século XIX (Werron, 2007), tendo a Europa como o núcleo difusor dos processos sociais globais, mas sobretudo questionar e revisar sua descrição da própria transição para a sociedade moderna, realizando uma profunda autocrítica. Seria preciso, portanto, rever a tese da transição à sociedade mundial funcionalmente diferenciada a fim de escapar da narrativa da singularidade ocidental (Chakrabarty, 2000:7), segundo a qual outras regiões recebem, sempre de fora para dentro, estruturas sociais e semânticas gestadas primeiramente na Europa.

O maior desafio para a teoria da sociedade mundial é o de recontar a história da modernidade, substituindo a narrativa única de uma diferenciação funcional desenvolvida inicialmente no interior da Europa e depois expandida para o resto do mundo por narrativas plurais sobre a experiência de cada contexto geo-histórico como parte do desenvolvimento "entrelaçado" (Randeria, 2000) e "múltiplo" (Eisenstadt, 2000) de sistemas funcionais globais (Grizelj e Kirschstein, 2014:12). É preciso, também na teoria dos sistemas, reescrever a história do ocidente a partir das relações e diferenças que o constituíram. 
O argumento principal é que é possível propor uma recepção da teoria da sociedade mundial de Niklas Luhmann que corrija seus componentes eurocêntricos, permitindo construir uma concepção não culturalista e não essencialista da América Latina. A ideia central é tratar processos e estruturas da regionalização como variações normais da modernidade global, e esta, por sua vez, enquanto dinâmica societária diferenciada e não estacionária. Nesta recepção crítica da sociologia de Luhmann, a construção da América Latina como regionalização semântica e estrutural deixa de ser vista como desvio, sob o signo da falta, da modernidade plena de outras regiões. A modernidade contemporânea não é identificada com nenhuma região específica do planeta, embora se reconheça a centralidade da Europa em sua emergência. Todas as regiões, assim como outras configurações estruturais, se constroem a partir da modernidade global, na qual estruturas neocoloniais se reproduzem, mas não constituem um sistema unitário como nas relações coloniais do passado pré-moderno, e sim um conjunto de relações centro/periferia fragmentadas pela lógica da diferenciação funcional da sociedade.

Há uma rica literatura sobre a modernidade global e suas variações regionais, com foco específico na América Latina. Nos aspectos centrais, a recepção que proponho da teoria da sociedade mundial de Luhmann como ponto de partida para uma "sociologia sistêmica pós-colonial" da América Latina coincide com as formulações de alguns dos mais interessantes e criativos esforços teóricos contemporâneos, como os de José Maurício Domingues (2008) e Carlos Gadea (2015). Para ambos, assim como para Luhmann, a modernidade contemporânea não é uma entidade que possa ser associada ontologicamente a uma região do planeta, mas uma dinâmica não estacionária que produz variações estruturais internas. Entre essas variações está a construção regionalizada e criativa de configurações espaço-tempo (Domingues, 2008:128), como no caso da América Latina, no bojo da expansão heterogênea da modernidade, de suas instituições (ou sistemas) e imaginários (ou semânticas), e em contato estruturante com tradições e histórias regionais, que, ao contrário de desaparecerem, se transformam no contato com a modernidade e condicionam em grande medida muitas de suas possibilidades em cada região. A ideia central compartilhada é enfatizar ao mesmo tempo o caráter global da modernidade e a heterogeneidade estrutural no espaço e no tempo de sua produção e reprodução, combinando o conceito de sociedade global com o conceito de regionalização. 
Outra importante semelhança entre minha proposta e as de Domingues (2008) e Gadea (2015) é a percepção da contingência das relações de desigualdade e dominação no processo de regionalização, destacando que os imaginários ou dispositivos normativos da modernidade não podem ser reduzidos ao colonialismo e às desigualdades econômicas entre centro e periferia, sendo, ao contrário, também constituídos pelos critérios imanentes mobilizados na crítica social e científica do colonialismo e do neocolonialismo. A percepção de que a crítica pós e decolonial não transcende a modernidade e seus horizontes semânticos se baseia na descrição das relações entre centro, periferia e semiperiferia enquanto estruturas e processos contingentes da regionalização na sociedade mundial, por mais difícil e complexa que seja sua transformação real. A fonte principal dessa contingência está na pluralização das relações centro/periferia como resultado da diferenciação funcional da sociedade mundial (Domingues, 2008:131; Gadea, 2015:108), que faz com que, por exemplo, a periferização de um país na economia global não se traduza automaticamente em sua periferização na política global. A contingência e a pluralização estrutural das relações entre centro e periferia são a condição para a crítica ao colonialismo e ao neocolonialismo, tornando imanentes perspectivas que propõem transcender a modernidade, como a de Walter Mignolo.

O artigo está dividido em três partes. Na primeira, recapitulo as proximidades epistemológicas e ontológicas entre a teoria dos sistemas e os pós-colonialismos encontrados na literatura recente. Na segunda seção, esboço as linhas gerais de uma teoria sistêmica da modernidade submetida a um processo de descolonização e equipada para incluir o problema das hierarquias neocoloniais em sua (auto)descrição da sociedade. Na terceira parte, discuto como uma sociologia sistêmica pós-colonial, empenhada na observação da contingência das estruturas neocoloniais, pode servir para analisar a América Latina enquanto região da sociedade mundial moderna.

\section{TEORIA DOS SISTEMAS E TEORIAS PÓS-COLONIAIS}

Na última década, alguns trabalhos (Gonçalves, 2013; Grizelj e Kirschstein, 2014; Eckstein e Reinfandt, 2014) ressaltaram as afinidades entre a teoria luhmanniana dos sistemas e as teorias pós-coloniais e decoloniais. Em termos gerais, esses esforços destacam as enormes semelhanças epistemológicas e ontológicas entre as duas abordagens, especialmente o ponto de partida de uma teoria da diferença (em opo- 
sição às teorias das identidades, essências e fundamentos), a desconstrução da distinção ontológica entre sujeito e objeto e a ruptura com a ideia de um conhecimento neutro e desengajado de seus objetos, em favor de uma teoria do conhecimento em que o conhecer é uma das operações fundamentais (da autoconstituição) dos próprios objetos estudados.

Nesse contexto, cabe elucidar alguns pontos:

1) Teoria da diferença: em que pese a grande diversidade no interior do que se convencionou chamar de teorias pós-coloniais ou decoloniais, todas elas comungam com a teoria dos sistemas de Luhmann a premissa de que as realidades constituídas por sentido (social e psíquica) são, em todas as instâncias, diferenças entre o sentido selecionado e o não selecionado, mas reproduzido como possibilidade, como virtualidade em face da qual o sentido selecionado torna-se contingente. Em vez de partir da existência de determinadas identidades, estruturas e referências fixas, o postulado é que toda identidade, estrutura e referência é constituída por operações de sentido que traçam distinções: o "ocidente" precisa se distinguir do "oriente" (Eduard Said, 2007) ou do "resto do mundo" (Stuart Hall, 1992) para formar e reproduzir sua identidade de "ocidente"; o sistema precisa se distinguir do ambiente para formar e reproduzir sua identidade de sistema (Gonçalves, 2013; Eckstein e Reinfandt, 2014);

2) Desconstrução da distinção ontológica entre sujeito e objeto: outra grande semelhança entre as duas abordagens aqui tratadas é a crítica à filosofia/ontologia do sujeito que concebe este último como uma instância cognitiva ontologicamente separada do mundo, nas esferas do conhecimento ou da ação prática. O cogito cartesiano perde, tanto para os pós-coloniais e decoloniais como para Luhmann e os luhmannianos, a condição de instância privilegiada do conhecimento e da ação, tornando-se uma construção histórica, contingente e precária das operações e discursos que também são responsáveis pela constituição dos objetos do conhecimento. O que se designa como sujeito e o que se designa como objeto são constituídos pelas mesmas operações de sentido que produzem o conhecimento enquanto saber situado no mundo, sobre o mundo e para o mundo. Ou, como diria Luhmann, observador e observado resultam da mesma base operativa (1997:875); 
3) Ruptura com a ideia de um conhecimento neutro e desengajado: a terceira importante afinidade epistemológica e ontológica entre teoria dos sistemas e teorias pós-coloniais e decoloniais é a própria concepção de conhecimento que resulta das outras demais premissas. Para ambas, o conhecimento é sempre conhecimento engajado, ou seja, criado e reproduzido a partir de problemas reais, como o desafio do colonizador em estabilizar a diferença colonial (colonizador/colonizado) por meio de conceitos e semânticas que fixem ontologicamente a relação de superioridade/inferioridade moral entre os dois lados e legitimem sua reprodução; ou o desafio dos sistemas sociais em conhecer os efeitos do ambiente instável sobre a continuidade das operações sistêmicas. Mesmo que a modernidade científica seja descrita por Luhmann como constituída por um sistema funcional autopoiético fundado em operações que codificam e validam o conhecimento como (cientificamente) verdadeiro ou falso, a produção e a circulação de conhecimento científico, ainda que subordinadas ao imperativo de uma diferença binária funcionalmente especializada (o código verdadeiro/falso), são concretamente programadas e organizadas por influência de acoplamentos estruturais da ciência com os demais sistemas funcionais, como economia e política. Ou seja, se trata sempre de uma ciência influenciada (embora não determinada na complexidade interna de duas operações) pelo seu acoplamento ("engajamento") com as operações do ambiente societal (Neves, 2009, 2014). Na medida em que ciência é sempre ciência acoplada e organizada, ela é sempre condicionada por fatores extracientíficos locais, como interesses políticos (coloniais, anticoloniais e desenvolvimentistas), econômicos etc.

Aqui é importante fazer duas ressalvas. Primeiro, que as afinidades epistemológicas e ontológicas não ficam restritas a essas duas vertentes teóricas; elas se estendem também às abordagens pós-estruturalistas e pós-fundacionistas (Garcia da Costa e Peixoto Rodrigues, 2017) de autores como Ernesto Laclau e Chantal Mouffe e Judith Butler. Tais abordagens também recusam sistematicamente a ontologia das identidades, das essências, das substâncias, das "estruturas necessárias e profundas" (Unger, 2004) e dos fundamentos últimos em favor de uma perspectiva da diferença que privilegia as operações cognitivas e práticas de diferenciação, como as responsáveis pela construção da realidade social e de "fundamentos contingentes" (Butler, 1992). Além disso, é preciso ressaltar que a crítica epistemológica e ontológica que aproxima teoria dos sistemas, pós-colonialismo, pós-estruturalismo e pós-fundacionismo não é exclusividade, pelo menos no que diz respeito à prática de produ- 
zir e fazer circular a ciência social, dessas vertentes teóricas cujo vigor é contemporâneo ao fim da Guerra Fria e ao desafio de criticar os discursos científicos hegemônicos que emulam certa impossibilidade de alternativas aos padrões de sociabilidade do Atlântico Norte. A ruptura com o eurocentrismo não é, portanto, uma realização específica da crítica pós-colonial. Dentro da própria Sociologia, disciplina que recebe pouca atenção de pós-coloniais como Walter Mignolo, tal ruptura já foi realizada por diferentes correntes que analisam a modernidade e sua expansão global (Domingues, 2011; Costa, 2006; Gadea, 2015). Na última parte deste artigo, discutirei brevemente as afinidades entre minha proposta de recepção "pós-colonial" da teoria luhmanniana da sociedade mundial e outras contribuições teóricas que, partindo de perspectivas teórico-sociais diferentes da minha, chegaram a formulações parecidas. Em relação à condição da América Latina enquanto região da modernidade, a única contribuição original do texto é a pretensão de demonstrar que formular uma concepção não essencialista do nosso território a partir da teoria de Luhmann também é possível.

As teorias pós-coloniais e decoloniais contemporâneas, apesar de diferenças de orientação teórico-filosófica, possuem uma concepção comum sobre o social, em grande medida distinta da teoria luhmanniana dos sistemas sociais. Embora compartilhem com Luhmann o ponto de partida de uma teoria da diferença, tais teorias, assim como as teses "pós-estruturalistas" do poder (Holmes, 2013), tendem a subsumir todas as diferenças sociais à dimensão política: "as diferenças são sempre formas de assimetria de poder entre povos" (Gonçalves, 2013:263). Em vez de trabalhar, como faz Luhmann, com a ideia de diferenciação dos tipos de práticas sociais, as teorias pós-coloniais e decoloniais alargam ao máximo a concepção do "político", partindo da premissa de que todas as dessemelhanças encontradas na sociedade são, no fundo, diferenças de poder ou delas resultantes. Enquanto em Luhmann a política seria uma das formas contingentes assumidas pelo social - precisamente enquanto forma funcionalmente diferenciada de comunicação -, ao lado de outras, como a economia e a religião, para as teorias pós-coloniais e decoloniais o social é sempre político.

Esse alargamento do político pode ser encontrado claramente no conceito de "colonialidade do poder" de Anibal Quijano (1997), amplamente aceito e utilizado como categoria-chave no pensamento decolonial latino-americano (Mignolo, 2002). A “colonialidade" é a estrutura hierárquica de dominação, criada a partir do circuito comercial do 


\section{Roberto Dutra}

Atlântico no século XVI, que produz suas próprias unidades dominadas e dominantes, seja em termos institucionais, com o sistema colonial e neocolonial de Estados centrais e periféricos, seja em termos socioculturais, com os processos de construção e universalização de etnias e raças enquanto critérios de classificação social hierarquizante de povos e posições na divisão do trabalho (Quijano e Wallerstein, 1992). A colonialidade é precisamente a estrutura hierárquica, formal ou não, que confere sentido geral, duradouro e definidor às relações entre um conjunto de Estados e identidades étnico-raciais ("geo-históricas" diria Mignolo) no sistema-mundo que emerge com o circuito comercial e colonial do Atlântico. Dessa maneira,

[...] mesmo quando o status colonial formal chega a seu fim, não acaba a colonialidade. Ela persiste na forma de uma hierarquia sociocultural entre europeus e não europeus. É importante entender que todos os Estados neste sistema interestatal são criações novas - daqueles no topo àqueles na base da hierarquia. (Quijano e Wallerstein, 1992:550)

A hierarquia da colonialidade é a estrutura de dominação que subsistiria a todas as transições, inclusive à transição para a diferenciação funcional, delimitada pelo fim do colonialismo político-administrativo e pela criação de Estados-nacionais formalmente autônomos.

Assim como os Direitos do Homem e a igualdade formal entre indivíduos, desde o jovem Marx, seriam meras ideologias para reproduzir e legitimar as desigualdades materiais entre as classes, o ideal igualitário entre povos e nações, embutido na independência formal de ex-colônias e sancionado como meta coletiva pelo atual sistema da ONU, assim como a própria ideia de diferenciação funcional, não seriam também mais do que fenômenos ideológicos que emergem para justificar desigualdades regionais (Gonçalves, 2017). A diferenciação funcional estaria sempre subordinada à hierarquia da colonialidade. Dessa forma, enquanto esfera primária de produção de diferenças e desigualdades no interior do sistema-mundo moderno/(neo)colonial,

[...] a hierarquia da colonialidade se manifesta em todos os domínios - político, econômico e, não menos importante, na esfera cultural. A hierarquia reproduz a si mesma no tempo, embora sempre tenha sido possível para poucos Estados modificar sua posição na hierarquia. Mas uma mudança na ordem das posições não perturba a existência contínua da hierarquia. (Quijano e Wallerstein, 1992:550) 
Na próxima seção, esboço as linhas gerais de uma teoria sistêmica da modernidade submetida a um processo de descolonização e equipada para incluir o problema das hierarquias neocoloniais em sua (auto) descrição da sociedade. Apesar de precisar de algumas correções em seu conteúdo eurocêntrico, a teoria dos sistemas possui considerável sensibilidade para diferenças regionais, além de formular conceitos interessantes para observá-las.

\section{POR UMA SOCIOLOGIA SISTÊMICA PÓS-COLONIAL}

Como seria uma teoria sistêmica da sociedade mundial submetida ao processo de descolonização, ou seja, que reflita sobre o lugar e os efeitos da "diferença colonial" na construção de seu objeto? Como seria a teoria da diferenciação funcional resultante desse processo? Qual o lugar da América Latina, e de outras regiões do Sul global ou da periferia, na constituição de sistemas funcionais globais? Proponho, nesta segunda parte do artigo, os elementos indispensáveis para construir uma Sociologia sistêmica pós-colonial da modernidade na América Latina.

O ponto de partida é a constatação de que a teoria da sociedade mundial é sensível às variações regionais do social. A diferenciação funcional, como forma primária da constituição de subsistemas da sociedade global, não postula a evolução convergente das regiões do planeta integradas e constituídas com a formação das sociabilidades globais. Ao contrário, à medida que promove a pluralização, a universalização, mas também a descentralização das formas e práticas de comparação social que conferem orientação identitária a regiões, povos etc., a diferenciação funcional potencializa as possibilidades de condicionamento e variação regional das operações sistêmicas. Por essa razão, considero equivocada a crítica de que Luhmann postula uma causalidade global e homogeneizadora de estruturas sociais locais. A meu ver, o autor é claro a esse respeito, com tal crítica resultando de uma leitura apressada de seu conceito de sociedade mundial, identificando um elemento de homogeneização que nunca esteve presente em sua teoria. Vejamos:

Antes tende ser correta a premissa de que a diferenciação funcional, consolidada no nível da sociedade mundial, indica as estruturas que abrem, por sua vez, possibilidades para o condicionamento local. [...] Vista desta forma, a diferenciação funcional não é a condição de possibilidade das operações sistêmicas, mas antes a possibilidade do condicionamento des- 
tas operações. Disso resulta ao mesmo tempo uma dinâmica sistêmica que conduz a desenvolvimentos extremamente desiguais no interior da sociedade mundial. (Luhmann, 1997:811)

Exemplo claro dessa orientação teórica é o fato de Luhmann abandonar qualquer viés teleológico em sua análise da condição secular moderna, que leva em conta as diferentes formas regionais assumidas pela diferenciação entre religião e sociedade. Em vez de, por exemplo, seguir o caminho pré-fixado de uma retirada crescente da religião do espaço público como um correlato necessário da diferenciação entre religião e política, a abordagem luhmanniana deixa em aberto se (e como) a religião assume formas mais ou menos potentes na vida social moderna. Não há telos, seja este entendido em termos de declínio, de privatização, ou de desinstitucionalização; há sim evolução, comandada por uma incontornável dose de contingência e acaso. Portanto, diferenciação funcional e secularização, ao contrário de serem tratadas como ponto de chegada (telos) e modelo convergente para a relação entre religião e sociedade, são o ponto de partida para se compreender as diferentes formas e tendências (muitas vezes contraditórias) assumidas pelo desenvolvimento da religião na modernidade (Dutra, 2016b).

A teoria da sociedade de Luhmann articula adequadamente a unidade da sociedade global com a variação regional das estruturas sociais. Enquanto o conceito de diferenciação funcional demarca o nível global mais abstrato da constituição de sistemas e códigos funcionais, outras categorias focam as variadas formas através das quais os subsistemas funcionais globalmente diferenciados se relacionam entre si e condicionam suas operações de modo diverso em cada região. Importante aqui é a concepção de que as variações regionais, mesmo quando se constituem a partir de relações assimétricas de centro/periferia, podem ser compreendidas pelo modo específico como os sistemas sociais globais entram, em nível regional, em relações de interdependência (acoplamento estrutural) específicas com outros sistemas funcionais, assim como pelo desenvolvimento estrutural de cada sistema a partir do condicionamento de suas operações por "histórias locais". Desse modo, é possível atender à exigência pós-colonial de tratar os sistemas funcionais como global designs condicionados por local histories (Mignolo, 2002).

Além da bastante discutida análise sobre a diferenciação centro/periferia, a breve investigação de Luhmann sobre a semântica neocolonial - e as práticas de comparação hierarquizante que ela contribui 
para estruturar - dá testemunho de como se pode articular a unidade da sociedade global funcionalmente diferenciada com a variação das estruturas locais e regionais. $O$ foco de Luhmann não é a semântica da racialização construída e universalizada, segundo a crítica pós-colonial latino-americana, com a construção do circuito comercial do Atlântico no século XVI. A ausência dessa análise na obra de Luhmann se coaduna com sua narrativa eurocêntrica da transição para a sociedade global moderna, a qual negligencia, como veremos a seguir, o papel da diferença centro/periferia em tal transição.

No entanto, apesar deste viés eurocêntrico na descrição sociológica da transição, Luhmann não ignora completamente o papel da semântica neocolonial. A atenção que faltou para a racialização no período colonial entre os séculos XVI e XVIII foi, ainda que timidamente, dedicada ao surgimento de uma semântica da desigualdade neocolonial específica da sociedade moderna, orientada não pelo conceito de raça, mas agora pelo conceito de cultura (que assim se coloca como o "equivalente funcional" do conceito de raça). Sua conclusão é que o conceito de cultura orienta comparações assimetrizantes no interior da sociedade mundial. No entanto, tais comparações também se guiam por outras semânticas, tornando o "culturalismo neocolonial" uma forma contingente de construir, interpretar e acessar o mundo social. As assimetrias que produz não se estabilizam como necessárias. Mesmo quando se reproduzem, o fazem em um horizonte conflituoso de possibilidades, a partir das quais as estruturas neocoloniais são vivenciadas como mutáveis.

No final do século XVIII, a Europa, em seu esforço de se definir como moderna, foi a primeira a conferir um sentido de construção identitária às comparações entre "culturas", nas escalas nacional, regional ou histórica. As comparações entre nações, inclusive as de forma hierarquizante, que estão no foco da crítica pós-colonial desde sempre, agora não são mais feitas primariamente em termos de raças, mas sim em termos de cultura (Luhmann, 1995b:145). Comparações implicam pressupor a contingência e a mutabilidade do que se compara. Não é possível comparar uma unidade social sem considerar que essa unidade poderia se apresentar de outro modo em face do pano de fundo de possibilidades mobilizado na comparação. Luhmann trata de comparações "culturalizadas" que se constituem no interior da expansão global dos sistemas funcionais e, na medida em que se pode especificar 
funcionalmente as condições de equivalência, não há limites históricos ou regionais para o que pode ser comparado. Haveria uma distinção da comparação cultural correspondente à diferenciação funcional.

Se o colonialismo do século XVI instituiu o primeiro sistema universal/planetário de classificação dos povos (a racialização das identidades), a diferenciação funcional, ao pluralizar as condições e esferas de comparação, promove uma multiplicidade de formas de classificação que se projetam para todo o globo. A dinâmica globalizante dos sistemas funcionais inclui a formação de relações de comparação, através das quais as operações sistêmicas são criticadas, observadas e avaliadas. A princípio, isso poderia resultar em enorme instabilidade e indeterminação. No entanto, esses efeitos são significativamente reduzidos por meio de assimetrias semânticas estabilizadas na comparação cultural. A partir do início do século XIX, segundo Luhmann, "encontramos um notável ressurgimento de oposições conceituais assimétricas" (1995b:146). O ponto de referência a partir do qual se compara produz assimetrias estáveis entre a "cultura que observa" e a "cultura observada" - como, por exemplo, as assimetrias "civilizado/ selvagem", "Ocidente/Oriente", "América do Norte/América Latina" etc. A assimetria é estável porque a inferioridade de um dos lados da diferença ("selvagem", "Oriente", "América Latina" etc.) torna impossível a inversão da diferença: o americano do norte protestante, universalista e democrático não pode ser confundido com o latino-americano católico, particularista e autoritário. No entanto, tal impossibilidade, junto com a estabilidade da assimetria, foi superada pelo dinamismo de direção e escala das comparações: "Se 'nós ocidentais' fomos pioneiros em inventar o 'Oriente', agora eles estão reinventando o 'Ocidente'” (Nassehi, 2010:391). A assimetria da semântica "América do Norte/América Latina" (Feres Júnior, 2004), desde o começo do século XX, também sofreu inversões com o processo de construção das identidades nacionais na América Latina. Agora não é apenas o latino-americano que é caracterizado como apresentando certo "déficit de racionalidade", mas também temos o norte-americano identificado como possuidor de um "déficit de capacidades afetivas". Além disso, a escala de comparação tem se tornando cada vez mais diferenciada e sensível a microvariações: antes apenas nações e povos eram tratados em termos de "culturas"; hoje, ao contrário, se culturaliza não apenas estilos de vida, mas quase tudo. 
A produção de diferenças e desigualdades regionais não pode ser reduzida a assimetrias entre Estados. No entanto, tanto o pós-colonialismo como a teoria dos sistemas, apesar de chegarem a esta conclusão comum, também ressaltam que a divisão do território global em Estados é um dos principais eixos de produção de desigualdades. Porém, enquanto as teorias pós-coloniais veem continuidade entre a hierarquia colonial de Estados e o sistema interestatal contemporâneo, mesmo com o fim do colonialismo formal, a teoria dos sistemas observa certa descontinuidade, pois o fim do colonialismo formal não é um fenômeno isolado, mas parte de um processo de diferenciação e fragmentação das esferas de sociabilidade de alcance global, o que resulta na diferenciação e fragmentação das próprias estruturas de desigualdade, incluindo as de caráter neocolonial. O pós-colonialismo reconhece a diferenciação da sociedade em esferas, mas ainda concebe a hierarquia neocolonial do capitalismo, institucionalizada no atual sistema de Estados, como o eixo central do "sistema-mundo". A teoria luhmanniana reconhece a existência, reprodução e até o aprofundamento de assimetrias do tipo centro/periferia, mas observa tais assimetrias como contingentes, plurais, assumindo a forma de diferenciações centro/periferia específicas de cada sistema funcional global.

Para Luhmann, a construção de Estados é um dos principais fatores de diferenciação centro/periferia e produção de variações regionais na estruturação e no condicionamento das operações sistêmicas. Embora a divisão do território global em Estados não represente a forma una da diferença centro/periferia, a organização estatal torna provável o acoplamento de diferenças dessa natureza, ainda que não o faça necessário. Países periféricos econômica e politicamente, como muitos (mas não todos) da América Latina, têm maior probabilidade de desenvolver formas periféricas de comunicação e práticas sociais em outros sistemas de função, como o direito e a ciência. Trata-se aqui de um processo de coprodução da própria diferença centro/periferia: os processos de periferização são constitutivos dos processos de centralização. Esse possível acoplamento de diferenças centro/periferia é mais provável em regiões com uma dependência de trajetória (path dependence) estruturada por formas periféricas de comunicação em sistemas funcionais como a política e a economia, mas ele não é necessário, seja porque a posição política e econômica das regiões se altera significativamente ao longo do tempo, seja porque nem todos os sistemas funcionais (como a religião e o sistema artístico) se juntam a esse acoplamento de diferenças. 
A diferenciação segmentar da política global em Estados nacionais, mesmo possuindo um caráter igualitário em termos formais, tende a se acoplar a desigualdades regionais anteriores (como o colonialismo) e a produzir novas assimetrias globais, especificamente modernas e estruturadas de modo plural em diferentes sistemas, mas que, em algumas regiões, ganham estrutura quase unitária (concêntrica, diria Aldo Mascanero) por meio do acoplamento de distintas diferenças centro/ periferia. Esse processo é territorializante: estrutura e é estruturado pelo desenvolvimento do sistema moderno de Estados-nacionais, mas não esgota as possibilidades de evolução do sistema como um todo, ou dos Estados em particular. A política moderna, mesmo admitindo, produzindo e amplificando diferenças neocoloniais, as torna contingentes, não somente no que se refere aos discursos e autodescrições anticoloniais presentes em muitos movimentos de libertação nacional, mas também no que diz respeito à efetiva transformação da posição de muitas regiões e Estados no âmbito de sistemas como a economia, a política, a educação e a ciência. Os exemplos da Ásia são os mais incontestes, mas não se deve esquecer que o Brasil, entre as décadas de 1930 e 1970, passou a figurar de modo permanente entre as dez maiores economias nacionais do mundo, alcançando posições de destaque igualmente claras em outros sistemas, como o esporte, as artes e a religião.

Com base na leitura que Heintz e Werron (2011) fazem do conceito de sociedade mundial, é possível interpretar a integração da América Latina na sociedade funcionalmente diferenciada como resultado de práticas de comparação entre unidades sociais espacialmente distantes em uma mesma sociedade mundial. Com isso, transcendemos a dicotomia espacial externo/interno e definimos esse processo de integração como resultado da própria globalização dos sistemas funcionais. A interpretação que ambos fazem da teoria luhmanniana é interessante para analisar a transição para a diferenciação funcional na América Latina porque a autonomização de esferas sociais observadas na região desde a primeira metade do século XIX não pode ser compreendida sem levarmos em conta as comparações sociais dos contextos locais com referências "estrangeiras". Categorias como subdesenvolvimento e periferia, que orientam a observação externa e a auto-observação interna das "singularidades" da região em determinados sistemas funcionais (especialmente na economia, no direito, na ciência e na política), pressupõem e integram a região em um horizonte global de referências e práticas comparativas. 
Na medida em que entendemos que a teoria luhmanniana permite combinar a unidade da sociedade mundial com a variação dos condicionamentos locais, temos à mão uma abordagem com enorme potencial para observar sociologicamente diferenças regionais. Uma direção analítica bastante promissora, apontada por Luhmann, consiste em tomar a diferenciação segmentar do sistema político global - ou seja, a base sistêmica dos processos de formação de Estados e regionalização centralizante e periferizante - como interface de uma multiplicidade de acoplamentos estruturais que influenciam, por sua vez, os desenvolvimentos estruturais internos dos distintos sistemas envolvidos. Isso permite, em termos gerais, construir uma régua teórico-sistêmica para o tratamento comparativo de Estados nacionais e casos regionais e, em termos específicos, coloca sob perspectiva a comparação da força/debilidade dos Estados em influenciar as estruturas de desigualdade dos distintos sistemas funcionais por meio da politização de condicionamentos locais - com todos os paradoxos que essa empreitada envolve.

A questão norteadora pode ser assim formulada: quais acoplamentos estruturais, e em que tipo de contexto nacional/regional, possuem protagonismo evolutivo em influenciar o desenvolvimento de estruturas intrassistêmicas de inclusão e desigualdade social? Essa questão me ajuda a problematizar a singularidade das estruturas de desigualdades de maior relevância local (condicionamentos locais), na medida em que se constata, por exemplo, que em alguns Estados ou regiões da sociedade mundial essa singularidade reside na "debilidade" relativa dos acoplamentos estruturais que o Estado de bem-estar pode promover - em comparação com outros acoplamentos estruturais, como a dependência monetária - enquanto mecanismo de mediação da inclusão (Inklusionsvermittlung). A teoria luhmanniana prevê que, sem os mecanismos de mediação de inclusão do Estado de bem-estar, dos quais dependem sobretudo as chances de vida dos estratos sociais mais baixos, a inclusão nos diferentes sistemas funcionais torna-se diretamente acoplada ao dinheiro: "Grande parte da população mundial está exposta aos efeitos de mercados globais sem contar com a mediação de um Estado nacional forte" (Weiss, 2002:85).

Em termos regional e local, a diferenciação funcional é experimentada como um horizonte de possibilidades de organizar e reorganizar estruturas políticas, econômicas, educacionais, científicas etc., tendo os poderes do Estado como foco não de condução, mas de indução de processos de inovação estrutural em distintas esferas sociais. Assim 
como em outros casos, a ruptura com o colonialismo e a formação de Estados territoriais conduzem a uma ampliação das possibilidades operativas dos sistemas funcionais (Luhmann, 1997:711). Para Alois Hahn (1993:198), a diferenciação segmentar do sistema político mundial (sua divisão em Estados nacionais) está em relação de reforço mútuo com a dinamização de práticas sociais específicas dos sistemas funcionais.

Em vez de solapar a autonomia desses subsistemas, as relações de interdependência que eles estabelecem com a política (chamadas por Luhmann de acoplamentos estruturais) favorecem o desenvolvimento autônomo de cada um deles. É o caso, por exemplo, da tributação e do gasto público para a economia e da constituição para o direito, embora no caso dos programas de desenvolvimento e projetos normativos (como fica mais nítido no que se refere ao Estado de bem-estar) a impossibilidade de controle estatal centralizado dos sistemas funcionais seja colocada em segundo plano para dar legitimidade à postulação de uma unidade territorial (impossivelmente operativa) dos sistemas funcionais.

Neste contexto, a diferenciação segmentar do sistema político global em Estados nacionais ancora, de modo permanente, não apenas a reprodução de hierarquias neocoloniais, mas também a condição de sua crítica. Ao se separar de uma concepção de ordem hierárquica natural, a política moderna e outros sistemas, como a educação, as artes, as ciências e a religião, se convertem em mundos a partir dos quais se pode observar tais hierarquias como contingentes e atuar na sua transformação estrutural. A "rebeldia nacional" (Unger, 2008) nunca deixou de estar presente como um fator político facilitador desses processos de transição, especialmente na transformação da estrutura do sistema global de Estados.

Nesse sistema, desigualdades interestatais promovem, simultaneamente, tanto espaços nacionais com estruturas de desigualdades específicas e territorialmente delimitadas como espaços transnacionais, nos quais o poder relativo de cada Estado-nação se converte nas liberdades de movimento e inclusão diferenciais conferidas ou negadas aos cidadãos de diferentes Estados e/ou regiões desprovidas de Estados efetivos (Weiss, 2017). Luhmann (2008:123) atribui ao Estado-nação, no interior da sociedade global, um papel de "equivalente funcional" da estrutura de classes no interior dos Estados-nacionais: ambos produzem, em diferentes contextos e escalas, um acoplamento de desi- 
gualdades, programadas em cada sistema de função, mas ao mesmo tempo coestruturadas pelo poder relativo de cada Estado no sentido de promover formas de inclusão para sua população nas distintas esferas da sociedade. Esse poder relativo resulta na formação não de fronteiras societárias nacionais, mas sim de posições sociais específicas, cujos efeitos estruturais sobre as desigualdades são simultaneamente internos (Bommes, 2004) e externos (Weiss, 2002).

Na Sociologia latino-americana, as chamadas "teorias da dependência" costumam variar em relação à observação da contingência das estruturas neocoloniais e das relações entre centro e periferia, especialmente no papel que conferem ao Estado e à política na produção e reprodução das estruturas sociais da dependência e do subdesenvolvimento. Comparando, por exemplo, as concepções de Andre Gunder Frank (1967) e de Fernando Henrique Cardoso e Enzo Faletto (1969) vemos que, enquanto para o primeiro o desenvolvimento do centro leva necessariamente ao subdesenvolvimento da periferia, uma relação necessária que só poderia ser rompida pela "revolução socialista", para os últimos a dinâmica política e as coalizões de classe específicas de cada país permitem romper com essa visão determinista, observando um componente decisivo de contingência na relação entre dependência e desenvolvimento, seja no sentido de admitir caminhos diversos de mitigação ou superação da dependência, seja no sentido de conceber formas de desenvolvimento com dependência. Para Domingues, os quadros de referência da análise de Cardoso e Faletto permanecem atuais para interpretar as reconfigurações nas relações entre centro e periferia, embora o ensaísta ressalte a necessidade de ampliar tais quadros, incluindo tanto uma maior diferenciação no grau de dependência (explorando a categoria de semiperiferia) como outras esferas da vida social, como a cultura, enfatizando com isso o caráter multidimensional e pluralizado das relações entre centro e periferia (Domingues, 2010:23).

Assim ampliado, o quadro de referência de dependência e desenvolvimento na América Latina (Cardoso e Faletto, 1969) torna-se compatível com minha proposta de recepção "pós-colonial" da teoria da sociedade mundial de Niklas Luhmann, inclusive porque tal proposta se orienta pelo mesmo esforço, cultivado e desenvolvido no ambiente intelectual do "marxismo paulista" (Bortoluci, 2013), de onde emerge a teoria da dependência defendida por Fernando Henrique Cardoso, 
que almeja corrigir o viés eurocêntrico de teorias sociais elaboradas na Europa com o intuito de interpretar as "periferias" como constitutivas da modernidade.

Na próxima seção discutirei como uma Sociologia sistêmica pós-colonial, empenhada na observação da contingência de estruturas neocoloniais, pode servir para analisar a América Latina como região da sociedade mundial moderna, dialogando com outras contribuições da Sociologia latino-americana, como as "teorias da dependência", as análises mais recentes que relacionam a expansão heterogênea da modernidade com a regionalização.

\section{AMÉRICA LATINA E A CONTINGÊNCIA DAS DESIGUALDADES NEOCOLONIAIS}

A diferenciação segmentar do sistema político global não assume a forma de um todo igualitário, sem disparidades de poder significativas entre os Estados. No entanto, as assimetrias neocoloniais, embora resultem em diferenças de poder com potencial de tradução para distintas esferas sociais, não anulam o horizonte igualitário (o ideal pós-colonial de "autodeterminação dos povos") presente na formação dos Estados-nacionais. Ao contrário do colonialismo, o sistema global de Estados não conta com uma cosmologia que logre naturalizar a colonialidade enquanto forma de diferenciação primária da sociedade. E a contribuição crítica mais importante da teoria dos sistemas para o pós-colonialismo é precisamente observar sistematicamente a contingência da colonialidade enquanto estrutura de desigualdade produzida e reproduzida em uma sociedade primariamente segmentada em sistemas funcionais.

Com a constituição de sistemas funcionais globais e diferenciados, as assimetrias neocoloniais, do mesmo modo que as desigualdades de classe, gênero e etnia, perdem seu caráter "necessário" do ponto de vista de sua estruturação e legitimação, sendo recolocadas em um horizonte interno de críticas e alternativas. O unitarismo estrutural característico do colonialismo, com sua relação entre "centro" e "periferia" válida em todas as dimensões, é rompido pela diferenciação funcional, que impõe uma fragmentação da oposição centro/periferia em múltiplas diferenças entre "centros" e "periferias" no interior dos distintos sistemas funcionais. O primado da "diferença colonial", definidor do colonialismo, implicava a existência global de uma episteme 
(estrutura semântica e social em Luhmann) unitária que classifica e hierarquiza raças e povos: "A ideia de raça ou pureza de sangue, tal como expressa no século XVI, tornou-se o princípio básico para classificar e ranquear povos por todo o planeta, redefinindo identidades e justificando o trabalho escravo" (Mignolo, 2002:83).

A diferenciação funcional não apenas fragmenta e rompe com o primado da colonialidade; ela também produz o horizonte e as condições de possibilidade de crítica e transformação semântica e estrutural das assimetrias entre povos, Estados e nações. O pós-colonialismo descuida de sua autorreflexão ao pressupor que faz uma crítica "externa" da colonialidade, como se o horizonte normativo de uma "humanidade compartilhada", que orienta em última instância a crítica pós-colonial (Mignolo, 2002:72), não dependesse de uma formação societária na qual a colonialidade não é a forma primária, necessária e naturalizada de constituição de relações e unidades sociais. A referência ao ideal de que "somos todos humanos", do qual Mignolo não escapa, é uma fonte conhecida da semântica moderna da inclusão de todas as pessoas nos sistemas funcionais do corpo social, correlata de uma sociedade pós-tradicional e pós-colonial, na qual diferenças ontológicas entre pessoas, grupos, povos, nações, classes, gêneros, etnias etc. podem ser observadas, em modo de segunda ordem, como construções arbitrárias passíveis de transformação, como problemas, e não mais como soluções inquestionáveis.

No contexto da América Latina, há dificuldades em escapar de uma leitura "neocolonial" (Gonçalves, 2017) da teoria luhmanniana da sociedade mundial funcionalmente diferenciada. Exemplo consolidado desse tipo de leitura é o trabalho de Marcelo Neves sobre os problemas de (des)diferenciação do Direito no Brasil, do qual resulta a tese geral da ausência de diferenciação funcional na América Latina (1992; 2012). Segundo ele, no Brasil e na América Latina, ao contrário do que aconteceria nos países centrais da Europa e da América do Norte, o primado da diferenciação funcional seria solapado pela "corrupção sistêmica estrutural" típica da "modernidade negativa" ou da "periferia".

O fundamento empírico desta tese consiste na junção de dois fenômenos que seriam típicos da modernidade periférica: em países como o Brasil não se pode encontrar nem uma "realização adequada da autonomia sistêmica [...] nem a realização dos direitos de cidadania 
como instituição de inclusão social" (2006:257). Sua leitura da teoria luhmanniana postula uma relação necessária entre o primado da diferenciação funcional e a realização do imperativo da inclusão universal de todos os indivíduos em cada um dos sistemas funcionais (1992:160). Desse modo, em sua perspectiva comparativa as "regiões centrais" (Europa e América do Norte) são definidas pelo primado da diferenciação funcional e pela realização da inclusão universal, enquanto as "regiões periféricas" são vistas como desvio em relação ao centro, como exemplos de "modernidade negativa" (2006:257).

O problema é que esse fundamento empírico é frágil e caricatural. A ideia de que na Europa e nos Estados Unidos a inclusão e a exclusão nos sistemas funcionais são efetivamente estruturadas por mecanismos universalistas e pautadas exclusivamente por normas constitucionais ignora a realidade de desigualdades sociais estruturadas segundo mecanismos particularistas. Para superar tal problema é necessária uma correção teórica sobre a tese luhmanniana do primado da diferenciação funcional. Como tentei demonstrar alhures (2013; 2016a), a diferenciação funcional constitui o pano de fundo global para observação de regiões (ou outras unidades sociais/socioespaciais, como países, classes, etnias etc.) como desviantes em relação a outras regiões, de acordo com os padrões de autonomia sistêmica e inclusão tomados como referência comparativa. Ocorre, porém, que as referências comparativas são localizadas sempre na Europa e nos E.U.A. Ainda que haja permanentes desigualdades na capacidade de estabelecer - e estabelecer-se como - referência comparativa, a teoria de Luhmann, apesar de seus componentes eurocêntricos, prevê uma pluralização e não uma insuperável concentração territorial das unidades tomadas como critério de sucesso na realização das funções sociais diferenciadas na modernidade.

Não se trata, a princípio, de negar que a realização do imperativo da inclusão plena foi mais exitosa no "centro" do que na "periferia", mas de recusar a mitificação de regiões. Nesse caminho desembocam análises como a de Neves, que interpretam as contradições e variações referentes à realização da diferenciação funcional na "periferia" como partes de uma realidade de tipo distinto daquela do "centro".

As críticas pós-coloniais, especialmente a de Mignolo, com sua associação à teoria do Sistema-Mundo e com seu foco na dimensão cognitiva da colonialidade eurocêntrica, desejam a ampliação do leque 
de modelos normativos sobre a vida política, econômica e jurídica de povos, nações e países da "periferia", e com isso a pluralização das referências comparativas globais em todas as esferas da sociedade. O interesse de Mignolo pela Filosofia e Ciência Social produzidas na África e na Ásia testemunham exatamente esta pluralização no interior do sistema científico global, no qual o intelectual argentino sempre teve ampla liberdade de circulação, fala e audiência. Sua pretensão intelectual (e também política) pôde ser atendida com as ferramentas da teoria da sociedade de Luhmann, na qual a sociedade mundial é composta por uma variedade de referências comparativas (Schmidt, 2012), entre as quais estão os Estados nacionais, mas não apenas eles. E com a vantagem de se trabalhar de modo mais consequente com a questão da autologia: refletir sobre a condição social a partir da própria observação crítica pós-colonial.

Neste processo de pluralização, que comporta desigualdades globais permanentes e extremas, é preciso problematizar as chamadas "sociedades nacionais" como unidades de análise e comparação sociológica, sem, no entanto, deixar de registrar que, na prática social, elas são reiteradamente tomadas como unidades de observação comparativa no contexto mundial. É preciso problematizar sem ignorar que as fronteiras nacionais são estruturas reais e efetivas na produção de desigualdades globais (Weiss, 2017). Dito de outro modo: é necessário atingir o ponto em que os traços característicos da modernidade "deixam de ser associados exclusivamente às experiências de sociedades nacionais, tanto em suas origens como em seus desenvolvimentos posteriores" (Tavolaro, 2014:665).

A leitura da teoria de Luhmann realizada por Aldo Mascareño (2003; 2012) propõe uma alternativa à caracterização da modernidade na América Latina pelo critério do déficit de diferenciação e inclusão. Sua inovação é a diferença entre as variantes policêntrica e concêntrica da diferenciação funcional. Enquanto a variante policêntrica seria vigente na Europa e na América do Norte, a concêntrica caracterizaria a modernidade latino-americana. No entanto, essa inovação, ao tomar o Atlântico Norte como o caso de realização das potencialidades de autonomia e descentralização sistêmico-funcional com sua estrutura policêntrica, acaba reproduzindo o modelo neocolonial de comparação, no qual o Atlântico Norte é o parâmetro natural das realizações socioculturais da modernidade. Para Mascareño, 


\title{
Roberto Dutra
}

\begin{abstract}
Ao contrário das sociedades europeias, cujo processo de diferenciação funcional resultou num padrão de organização social policêntrico, em que os sistemas sociais operam de forma descentralizada (autônoma, mas acoplada), estabelecendo pontes comunicativas que lhes permitem funcionar de forma coordenada, as sociedades latino-americanas têm se caracterizado por serem estruturadas em torno de um sistema dominante. Com isso, o desenvolvimento autônomo de cada esfera tornou-se dependente do sistema central, e os acoplamentos foram transformados em processos de desdiferenciação que dificultaram a implantação da especialização de funções. No centro desta estruturação particular tem se situado o sistema político e sua referência descritiva, o Estado. Desde a origem das Repúblicas, a política, mesmo sem legitimidade jurídica, tem sido o sistema funcional que tem definido as diretrizes para o desenvolvimento de outras esferas. Exemplos claros dessa indiferenciação são a história dos Estados de exceção na América Latina (indiferenciação entre política e direito) e o modelo planejado de substituição de importações (indiferenciação entre política e economia. (2003:9-10)
\end{abstract}

Como se pode notar na citação acima, a análise de Mascareño atribui o caráter concêntrico da diferenciação funcional na América Latina ao papel centralizador do Estado, o qual seria responsável por induzir processos de desdiferenciação entre a política e outros sistemas funcionais, como Direito e Economia. Assim como a análise de Neves, a de Mascareño também parece padecer de alguns problemas empíricos, embora não dos mesmos. São eles:

1) Generalizar o papel do Estado, como se seu protagonismo na construção de ordens sociais concêntricas fosse o mesmo em todo o continente latino-americano. Essa narrativa, em afinidade com o discurso liberal-conversador que atribui sempre ao Estado a fonte dos problemas e à sua redução a fonte de soluções, não leva em conta as enormes diferenças não só entre as capacidades estatais dos países (entre Brasil e Bolívia, por exemplo), como aquelas internas aos próprios países. Como vimos acima, a reconstrução histórico-sociológica (Hahn, 1993) evidencia que não há, pelo menos como relação causal necessária, um jogo de soma zero entre construção e fortalecimento dos papéis do Estado e a diferenciação de outros sistemas funcionais (Gadea, 2015:108). Levando em conta esse dado histórico, o papel dos Estados nacionais na América Latina, sobretudo nos períodos de maior fortalecimento de suas capacidades, como no nacional-desenvolvimentismo do século $X X$, revela-se muito semelhante àquele desempenhado ontem e hoje na Europa e nos Estados Unidos; 
2) A reprodução de caricaturas regionais, o que chamei alhures (Dutra, 2016a) de "ontologização da região", é outro problema empírico decorrente da identificação de padrões de diferenciação funcional com países ou regiões inteiras, como se a semântica territorial (Norte/Sul, por exemplo) engendrasse uma estrutura hierárquica entre centro e periferia unitária e totalizante. Os processos de periferização e centralização de práticas sociais às vezes obedecem a fronteiras territoriais, nacionais ou regionais, mas não o fazem sempre e nunca de modo necessário. Sua localização territorial é contingente. Nos países periféricos há, por exemplo, processos de centralização na ciência (Neves, 2009), assim como há processos de periferização em países centrais. Ou seja, para construir uma teoria sistêmica pós-colonial da modernidade na América Latina é preciso não substituir o nacionalismo pelo regionalismo metodológico, rompendo efetivamente o obstáculo epistemológico regionalista caricatural de pressupor um padrão especificamente "latino-americano" de modernidade, seja ela concêntrica, negativa, ou periférica, pois esses atributos não estão ontologicamente ligados a nenhuma região.

Neste contexto, a busca por concepções não ontologizantes da América Latina como região da sociedade mundial é a principal tarefa da teoria sociológica preocupada com nosso continente (Tavolaro, 2017:226). Essa busca tem sido exitosa em algumas importantes formulações teóricas (Domingues, 2008; Gadea, 2015). Para Domingues (2008:126), a América Latina é o resultado da expansão heterogênea, desigual, contraditória e criativa ("desenvolvimento desigual e combinado" no sentido de Trotsky) da modernidade global, com sua capacidade de adaptação em encontros civilizatórios, seja pela violência e destruição, seja pela oferta de um horizonte normativo atraente, com seus valores de igualdade, liberdade e solidariedade. Como a modernidade contemporânea não pode ser identificada com nenhuma região do planeta, ainda que se deva reconhecer a centralidade da Europa em seu surgimento, a regionalização da América Latina deve ser vista como uma "construção espaço-temporal regionalizada" (Domingues, 2008:128), ao lado de outros processos de regionalização da mesma natureza e sem nenhuma singularidade ontológica. Neste quadro teórico, a construção de desigualdades regionais do tipo centro/periferia não é vista como eixo estrutural necessário da modernidade global (o que chamo de "primado da diferença colonial"), mas sim como um processo contingente e multidimensional. 
Outra contribuição que supera concepções ontologizantes da América Latina enquanto região da modernidade global é a de Gadea. Partindo de uma definição de modernidade como "ordem social dinâmica" - que se aproxima tanto da visão de Domingues como da ideia luhmanniana de "sociedade não estacionária" -, Gadea define o continente latino-americano como uma "experiência cultural sedimentada" que resulta exatamente da expansão das instituições especializadas (diferenciação societal) e dos dispositivos normativos da modernidade. Seu foco principal são os processos seletivos de universalização de normas, generalização de valores e formalização de interações (2015:106) que promovem a "institucionalização" de maneiras de agir e estar no mundo associadas a um "determinado esquema classificatório" (p. 113) proveniente da expansão global de "instituições especializadas" (p. 108).

Diante dessas contribuições, a Sociologia sistêmica pós-colonial que proponho aqui é original apenas no sentido de pretender demonstrar que uma concepção sobre a América Latina enquanto região da sociedade global a partir da teoria social de Luhmann também é possível. Minha proposta resulta em concepção semelhante, e sua pretensão é apenas demonstrar que a teoria da sociedade mundial luhmanniana pode render uma visão não ontológica da América Latina e dialogar com essas e outras contribuições.

Uma visão luhmanniana não ontológica da América Latina só é possível rompendo-se com a tese de que a diferenciação funcional não constitui a forma primária de formação de subsistemas sociais no continente, como encontramos na recepção que Marcelo Neves (1992; 2006; 2012) faz de Luhmann. É necessário reconstruir a relação entre modernidade periférica e diferenciação funcional, representando processos de periferização/centralização como parte da dinâmica de expansão e globalização de sistemas funcionais: "O papel da América Latina não pode ser descrito como se ela pertencesse a uma periferia generalizada, não específica, que permanece de algum modo isolada da diferenciação funcional" (Kleinschmidt e Pérez, 2017:11). A modernidade periférica segue a lógica da diferenciação funcional, pois os processos de periferização, plurais e multidimensionais, ocorrem no interior dos subsistemas funcionalmente diferenciados. Nesse sentido, em uma sociedade mundial funcionalmente diferenciada, regiões devem ser "descritas em termos de sua relação com a diferenciação funcional enquanto sua característica primária" (Kleinschmidt e Pérez, 2017:12). 
As relações constitutivas da regionalização com a sociedade mundial funcionalmente diferenciada devem ser concebidas em termos estruturais e semânticos. Em termos estruturais, a expansão global, heterogênea e desigual da sociedade funcionalmente diferenciada é institucionalizada com processos de regionalização que concretizam de modo específico, sob a forma de programas, acoplamentos estruturais e outras estruturas sociais de relevância especificamente regional, as referências abstratas representadas pelos códigos binários dos sistemas funcionais. Nesse processo de regionalização e concretização, estruturas pré-modernas, como formações estamentais e segmentares, são ressignificadas no interior da lógica dos sistemas funcionais, formando "dependências de trajetória" específicas, de acordo com os condicionamentos históricos de cada região. Em termos semânticos, destaca-se o imaginário de integração regional que atua sobretudo como "avanço pré-adaptativo" em relação às estruturas sociais vigentes, fornecendo um horizonte normativo e cognitivo para tematizar problemas de inclusão e autonomia sistêmica (na Economia, na Política, no Direito etc.) em conformidade com as expectativas de inclusão e autonomia vigentes em outras regiões e na sociedade mundial como um todo. Desse modo,

\begin{abstract}
Projetos regionalistas na América Latina têm sua função na geração de semânticas que permitem a comunicação sobre certas características estruturais de inclusão e exclusão em termos compatíveis com os códigos dos sistemas funcionalmente diferenciados na sociedade mundial. Em muitos casos, os programas ambiciosos delineados em documentos oficiais servem como semânticas "pré-adaptativas" - que podem ser anteriores, compensatórias ou coconstitutivas da mudança socioestrutural. (Kleinschmidt e Pérez, 2017:14)
\end{abstract}

Em minha proposta de uma Sociologia sistêmica pós-colonial da América Latina, descompassos entre estrutura e semântica não são descritos como sintomas da ausência (ou do caráter puramente de "fachada") da diferenciação funcional na região, como encontramos no diagnóstico amplamente difundido da baixa institucionalização e da "debilidade do Direito e do constitucionalismo" (Gadea, 2015:114) como traços singulares do continente. Minha proposta não trata estes problemas de institucionalização, seja na Política, no Direito, ou em qualquer outro subsistema, como características singulares da região. A precariedade e a fragilidade das normas formais em orientar a ação e a vivência devem 
ser vistas como traços intrínsecos da vida social moderna enquanto dinâmica de expansão com exigências comportamentais improváveis e dependentes de muitos pressupostos (p. 119).

\section{CONSIDERAÇÕES FINAIS}

Neste artigo, defendemos a construção de uma Sociologia sistêmica pós-colonial como ferramenta promissora para analisar a América Latina como região da sociedade mundial moderna. Apesar das diferenças entre as teorias pós-coloniais e a teoria sistêmica luhmanniana da sociedade mundial, existem entre elas fortes premissas epistemológicas compartilhadas já apontadas pela literatura. No entanto, na construção de uma teoria da sociedade mundial elas parecem se distanciar: enquanto as teorias pós-coloniais tendem a pressupor um primado das desigualdades (neo)coloniais na produção de diferenças sociais regionais, a teoria de Luhmann postula o primado da diferenciação funcional entre subsistemas como ponto de partida para explicar essas diferenças. Meu argumento adota a tese de Luhmann sobre o primado da diferenciação funcional, enfatizando que ela estabelece os horizontes de possibilidades e os limites da crítica pós-colonial. Tal crítica é construída como uma observação da contingência das estruturas neocoloniais realizada no interior dos sistemas funcionais (como a Ciência Social, a Política, o Direito, a Literatura etc.) que pressupõe a superação do caráter sociocosmologicamente necessário das hierarquias coloniais, ainda que estruturas neocoloniais sejam construídas e reproduzidas. Apropriada desse modo, a Sociologia sistêmica de Luhmann pode contribuir para uma análise da América Latina que supere o viés eurocêntrico, sem recair em reducionismos, como a subsunção da modernidade a fenômenos de dominação e desigualdade. Meu argumento é que a teoria da sociedade mundial de Luhmann permite combinar variedade com unidade da modernidade, sem reduzir a variedade a fatores de poder e dominação, tampouco a déficits de modernidade ou diferenciação societal.

No entanto, adotamos uma das preocupações centrais (se não a central) da crítica pós-colonial: desconstruir a compreensão eurocêntrica sobre a história e as características constitutivas da modernidade. Nesse sentido, a construção de uma Sociologia sistêmica pós-colonial exige correção fundamental na narrativa luhmanniana sobre a gênese da sociedade funcionalmente diferenciada: é preciso rever a tese da transição à sociedade funcionalmente diferenciada, a fim de escapar da nar- 
rativa da singularidade ocidental (Chakrabarty, 2000:7), segundo a qual a modernidade emergiu primeiro na Europa e depois se expandiu para outros lugares. O maior desafio para a teoria da sociedade mundial é o de recontar a história da modernidade, substituindo a narrativa única de uma diferenciação funcional desenvolvida inicialmente no interior da Europa por narrativas plurais sobre a experiência de cada contexto geo-histórico com o desenvolvimento "entrelaçado" (Randeria, 2000) e "múltiplo" (Eisenstadt, 2000) de sistemas funcionais globais (Grizelj e Kirschstein, 2014:12). O componente mais eurocêntrico da teoria de Luhmann (ou seja, aquele que menos reflete sua preocupação tardia em conduzir sua própria teoria a um giro reflexivo sobre as diferenças regionais) é sua descrição da transição à sociedade funcionalmente diferenciada como um fenômeno interno à Europa até o século XVIII, para somente depois, nos séculos XIX e XX, globalizar-se e assumir conexões e referências fora desse cenário.

Possivelmente, como defende a crítica pós-colonial, a correção dessa narrativa inclui reavaliar o papel da diferença centro/periferia na descrição de tal transição. Para Luhmann, a transição, na Europa, se deu a partir da diferenciação estratificada entre nobres e povo comum, havendo um silenciamento das diferenças coloniais entre centro e periferia nesse processo. Não se trata de negar a centralidade da Europa no processo de surgimento da modernidade, mas sim de observá-la a partir da própria diferença centro/periferia, o que se configura como resultado de um diálogo crítico e produtivo entre a teoria dos sistemas e o pós-colonialismo. Como ressalta Domingues (2008:125-126), não é necessário negar a inegável - centralidade da Europa na formação inicial da modernidade para ressaltar o papel constitutivo que os contatos e entrelaçamentos com outras regiões do planeta tiveram nesse contexto.

Na minha proposta de uma Sociologia sistêmica pós-colonial da América Latina, a relevância destes contatos e entrelaçamentos da modernidade europeia em expansão com a história, as instituições e os imaginários pré-modernos do continente não reside na busca de uma perspectiva exterior à modernidade, mas sim de uma perspectiva interna, capaz de articular sociedade mundial e regionalização, escapando do falso binarismo entre regionalização moderna com reprodução necessária de estruturas neocoloniais e ruptura regional com a modernidade. Em vez de externalidade, a América Latina, mesmo 


\section{Roberto Dutra}

sendo palco de processos inequívocos e perenes de periferização, deve ser vista como fonte regional de alternativas estruturais e semânticas internas à própria modernidade.

Não se trata de fazer uma descrição externa da sociedade global a partir de sua exterioridade periférica, já que tal espaço não existe enquanto "lugar de enunciação", pois as periferias da modernidade foram internalizadas e fragmentadas pelo primado da diferenciação funcional. As possíveis contribuições de uma Sociologia sistêmica pós-colonial, críticas ou não, estão dentro do sistema da sociedade global. Na teoria dos sistemas, é impossível rejeitar a sociedade pela crítica, pois toda crítica é uma comunicação pertencente à sociedade, interna a ela. Só é possível rejeitar estruturas internas da sociedade apoiando-se nas operações da própria sociedade que transcendem essas estruturas, ou seja, que se deixam organizar por estruturas alternativas, que essas próprias operações podem selecionar ou não.

(Recebido para publicação em 21 de abril de 2018)

(Reapresentado em 13 de janeiro de 2019)

(Reapresentado em 1 de julho de 2019) (Aprovado para publicação em 10 de novembro de 2019)

\section{NOTAS}

1. Acoplamento estrutural deve ser entendido, segundo Luhmann, como o conceito que indica o momento de abertura dos sistemas funcionais operativamente fechados. Ele busca observar a seletividade nas relações de dependência entre os subsistemas. Em última instância, o esquema diferenciação-integração (Durkheim, Parsons) deve ser substituído pelo binômio autopoiesis-acoplamento estrutural (Luhmann, 1997:778).

2. Sobre a "equivalência funcional" entre os conceitos de "raça" e "cultura" na legitimação de desigualdades globais, ver a crítica de Jessé Souza à recepção de Luhmann no Brasil (2013).

3. Esta concepção "flutuante" dos processos de periferização e centralização na tradição luhmanniana pode ser encontrada de modo sintético em Di Georgi (2017:44): “Essa alteridade, contínuo produto residual da diferenciação e da inclusão universal, é um excedente que pode se localizar, mas que também pode ser livre dentro dos confins da sociedade. Sociedade a qual não conhece mais a periferia como espaço externo: as periferias agora são lugares sociais flutuantes da "periferização", do depósito da exclusão, da produção de excedente, da discriminação de alteridade".

4. Uma contribuição que chega a resultados similares, criticando certos reducionismos do trabalho de Walter Mignolo, é a de José Maurício Domingues (2011:57-88). 


\section{REFERÊNCIAS}

BOATC , Manuela; COSTA, Sérgio. (2010), "Postkoloniale Soziologie: ein Programm". In: J. Reuter; Paula-Irene Villa (eds.), Postkoloniale Soziologie. Empirische Befunde, theoretische Anschlïsse, politische Intervention. Bielefeld: Transcript, pp. 69-91.

BOMMES, Michael. (2004), "Zur Bildung von Verteilungsordnungen in der funktional differenzierten Gesellschaft. Erläutert am Beispiel, ethnischer Ungleichheit' von Arbeitsmigranten". In: T. Schwinn (ed.), Differenzierung und Soziale Ungleichheit. Die zwei Soziologien und ihre Verknüpfung. Frankfurt a. M: Humanities Online.

BORTOLUCI, José Henrique. (2013), “Modernidade periférica e descolonização epistêmica. A contribuição do marxismo paulista". Revista Brasileira de Ciências Sociais, vol. 28, no 83 , pp. 167-184.

BUTLER, Judith. (1992), "Contingent foundations: feminisms and the question of 'postmodernism'". In: J. Butler; J. W. Scott (eds.), Feminists theorize the political. New York: Routledge, pp. 3-21.

CARDOSO, Fernando Henrique; FALETTO, Enzo. (1969), Dependencia y desarrollo en América Latina. Ensayo de interpretación sociológica. Cidade do México: Siglo XXI.

CHAKRABARTY, Dispesh. (2000), Provicializing Europe: postcolonial thought and historical difference. Princeton: University of Princeton.

COSTA, Everton G.; RODRIGUES, Leo Peixoto. (2017), “Teoria dos sistemas sociais, teoria do discurso e pós-fundacionismo: um diálogo possível”. In: L. P. Rodrigues; F. M. Neves (eds.), Niklas Luhmann. Sistemas sociais: ensaios teóricos. Porto Alegre: EDIPUCRS - Editora Universitária da PUC-RS, pp. 145-167.

COSTA, Sérgio. (2006), "Desprovincializando a Sociologia: a contribuição pós-colonial". Revista Brasileira de Ciências Sociais, vol. 21, nº 60, pp. 117-134.

DE GIORGI, Raffaele. (2017), “Periferias da Modernidade”. Revista Direito Mackenzie, vol. 11, $\mathrm{n}^{\circ} 2$, pp. 39-47.

DOMINGUES, José Maurício. (2011), Teoria crítica e (semi)periferia. Belo Horizonte: Ed. UFMG.

. (2010), "Revisitando dependência e desenvolvimento na América Latina". Série Cadernos Flasco, no 1 . Disponível em www.flacso.org.br. [Acesso em 22/5/2019)

. (2008), Latin America and contemporary modernity. A sociological interpretation. New York: Routledge.

DUTRA, Roberto. (2016a), "Diferenciação funcional e a Sociologia da modernidade brasileira". Política e Sociedade, vol. 15, n 34, pp. 77-109.

(2016b), “A universalidade da condição secular". Religião e sociedade, vol. 36, n 1 , pp. 151-174.

ECKSTEIN, Lars; REINFANDT, Christoph. (2014), "Luhmann in the Contact Zone: Zur Theorie einer transkulturellen Moderne”. In: M Grizelj; D. Kirschstein (eds.), Riskante Kontakte: Postkoloniale Theorien und Systemtheorie? Berlin: Kadmos, pp. 107-124.

EISENSTADT, Shmuel. N. (2000), Die Vielfalt der Moderne. Weilerswist: Velbrück Wissenschaft. 


\section{Roberto Dutra}

FERES JUNIOR, João. (2004), "Spanish America como o outro da América". Lua Nova, vol. 26, $\mathrm{n}^{\circ} 62$, pp. 69-91.

FRANK, Andre G. (1967), Development and underdevelopment in Latin America. Nova York: Monthly Review.

GADEA, Carlos. (2015), “Dinâmica da modernidade na América Latina: sociabilidades e institucionalização". Topoi, vol. 8, n 15, pp. 105-123.

GRIZELJ, Mario; KIRSCHSTEIN, Daniela (eds.). (2014), Riskante Kontakte: Postkoloniale Theorien und Systemtheorie? Berlin: Kadmos.

GONÇALVES, Guilherme Leite. (2013), "Pós-colonialismo e teoria dos sistemas: notas para uma agenda de pesquisa sobre o direito". In: R. Dutra; J. P. Bachur (eds.), Dossiê Niklas Luhmann. Belo Horizonte: Editora UFMG, pp. 249-278.

. (2017), "Functional differentiation as ideology of the (neo)colonial society". Thesis Eleven, vol. 143, n 1, pp. 70-81.

HAHN, Alois. (1993), "Identität und Nation in Europa”. Berliner Journal für Soziologie, no 3, pp. 193-203.

HALL, Stuart. (1992), "The West and the Rest: Discourse and Power". In: S. Hall; B. Gieben (eds.), Formations of Modernity. Cambridge UK: Polity Press in association with the Open University, pp. 275-320.

HEINTZ, Bettina; WERRON, Tobias. (2011), "Wie ist Globalisierung möglich? Zur Entstehung globaler Vergleichshorizonte am Beispiel von Wissenschaft und Sport". Kölner Zeitschrift für Soziologie und Sozialpsychologie, vol. 63, pp. 359-394.

HOLMES, Pablo. (2013), Verfassungsevolution in der Weltgesellschaft. Differenzierungsprobleme des Rechts und der Politik im Zeitalter der Global Governance. Baden-Baden: Nomos.

KLEINSCHMIDT, Jochen; PÉREZ, Pablo G. (2017), “Differentiation theory and the ontologies of regionalism in Latin America". Revista Brasileira de Politica Internacional, vol. 60, $\mathrm{n}^{\circ} 1$, pp. 1-21.

LUHMANN, Niklas. (2008), "Zum Begriff der sozialen Klasse”. In: Ideenevolution. Beiträge zur Wissenssoziologie. Frankfurt a. M.: Suhrkamp, pp. 72-131.

. (2002), Die Politik der Gesellschaft, André Kieserling (ed.), Frankfurt a. M: Suhrkamp. . (1997), Die Gesellschaft der Gesellschaft. vols. 1 e 2. Frankfurt a. M: Suhrkamp.

. (1995a), “Kausalität im Süden”. Soziale Systeme, n 1, pp. 7-2.

. (1995b), "Jenseits von Barbarei". In: Gesellschaftsstruktur und Semantik 4. Frankfurt a. M.: Suhrkamp, pp. 138-150.

. (1981), "Symbiotische Mechanismen". Soziologische Aufklärung 3. Opladen: Westdeutscher Verlag, pp. 228-244.

MASCAREÑO, Aldo. (2012), Die Moderne Lateinamerikas. Weltgesellschft, Region und funktionale Differenzierung. Bielefeld: transcript. 
(2003), “Teoría de sistemas de América Latina. Conceptos fundamentales para la descripción de una diferenciación funcional concêntrica". Revista Persona y Sociedad, vol. $17, \mathrm{n}^{\circ} 2$, pp. 9-26.

MIGLIEVICH-RIBEIRO, Adélia. (2014), "Por uma razão decolonial: desafios ético-políticos-epistemológicos à cosmovisão moderna". Civitas. Revista de Ciências Sociais, vol. 14, n 1 , pp. 66-80.

MIGNOLO, Walter. (2002), "The geopolitics of knowledge and the colonial difference". The South Atlantic Quarterly, vol. 1001, n 1, pp. 57-96.

NASSEHI, Armin. (2010), “Kultur im System: einige programmatische Bemerkungen zu einer systemtheoretisch informierten Kultursoziologie". In: M. Wohlrab-Sahr (ed.), Kultursoziologie: Paradigmen-Methoden - Fragstellungen. Wiesbaden: VS Verlag, pp. 375-395.

NEVES, Fabrício M. (2009), “A diferenciação centro-periferia como estratégia teórica básica para observar a produção científica". Revista de Sociologia e Política, vol. 17, n 34, pp. 241-252.

. (2014), "A contextualização da verdade ou como a ciência torna-se periférica". Civitas. Revista de Ciências Sociais, vol. 14, pp. 556-574.

NEVES, Marcelo. (2012), "Komplexitätssteigerung unter mangelhafter funktionaler Differenzierung. Das paradox der sozialen Entwicklung Lateinamerikas". In: P. Birle et al. (eds.), Durch Luhmanns Brille. Herausforderungen an Politik und an Recht in Latein Amerika und in der Weltgesellschaft. Wiesbaden: Springer/VS Verlag.

(2006), "Die Staaten im Zentrum und die Saaten an der Peripherie. Einige probleme mit Niklas Luhmanns Auffassung von den Staaten der Weltgesellschaft". Soziale systeme, vol. 12, pp. 247-273.

. (1992), Verfassung und Positivität des Rechts in der peripheren Moderne: eine theoretische Betrachtung und eine Interpretation des Falls Brasiliens. Berlin: Duncker und Humblot.

QUIJANO, Aníbal. (1997), "Colonialidad del poder, cultura y conocimiento en América Latin”. Anuario Mariateguiano, vol. 101, no 1, pp. 113-22.

; WALLERSTEIN, Immanuel. (1992), “Americanity as a concept, or the Americas in the modern world-system". International Social Science Journal, vol. 44, nº 4, pp. 549-557.

RANDERIA, Shalini. (2000), "Jenseits von Soziologie und soziokultureller Anthropologie: Zur Ortbestimmung der nichtwestlichen Welt in einer zukünftigen Sozialtheorie". In: U. Beck; A. Kieserling (eds.), Ortsbestimmung der Soziologie: Wie die kommenden Generation Gesellschaftswissenschaften betreiben will. Baden-Baden: Nomos, pp. 41-50.

SAID, Edward. (2007), Orientalismo. O Oriente como invenção do Ocidente. São Paulo: Companhia das Letras.

SCHMIDT, Volker. (2012), “Conceptualizing Global Modernity. A Tentative Sketch”. Working Paper Series, Departamento de Sociologia, National University of Singapore, pp. 1-52.

SOUZA, Jessé. (2013), “Niklas Luhmann, Marcelo Neves e o "culturalismo cibernético” da moderna teoria sistêmica”. In: R. Dutra; J. P. Bachur (eds.), Dossiê Niklas Luhmann. Belo Horizonte: Editora UFMG, pp. 149-182. 


\section{Roberto Dutra}

. (2011), “Jenseits von Zentrum und Peripherie. Über die symbolische Dimension des Kapitalismus. Berliner Journal für Soziologie, vol. 21, nº 1, pp. 23-38.

STÄHELI, Urs. (2009), "Die Konstruktion des Finanzpublikums: eine genealogische Analyse", in Rudolf Stichweh e Paul Windolf (eds), Inklusion und Exklusion: Analysen zur Sozialstruktur und sozialen Ungleichheit. Wiesbaden: VS Verlag, pp. 259-272.

TAVOLARO, Sérgio B. F. (2017), “Imagens de uma outra modernidade: Gilberto Freyre e o espaço-tempo latino-americano. Política \& Sociedade, vol. 15, nº 34, pp. 196-231.

. (2014), "A tese da singularidade brasileira revisitada: Desafios teóricos contemporâneos". Dados, vol. 57, no 3, pp. 633-673.

UNGER, Roberto Mangabeira. (2008), O que a esquerda deve propor. Rio de Janeiro: Civilização Brasileira.

. (2004), False necessity: anti-necessitarian social theory in the service of radical democracy. New York: Verso.

WEIß, Anja. (2017), Soziologie globaler Ungleichheiten. Frankfurt a. M.: Suhrkamp.

. (2002), "Raumrelationen als zentraler Aspekt weltweiter Ungleichheiten". Mittelweg, n' 2, pp. 76-91.

WERRON, Tobias. (2007), "Publika. Zur Globalisierungsdynbamik von Funktionssystemen”. Soziale Systeme, vol. 13, pp. 386-388. 


\section{RESUMO}

Por uma Sociologia Sistêmica Pós-Colonial da América Latina

As aproximações entre os pressupostos epistemológicos e ontológicos da teoria social de Niklas Luhmann e das abordagens pós-coloniais têm sido ressaltadas e desenvolvidas na última década. No entanto, levantam-se sérias dúvidas sobre a possibilidade da teoria da sociedade de Luhmann se desvencilhar de seu ponto de vista eurocêntrico. Neste artigo propomos, em linhas gerais, como se poderia superar esse impasse na teoria sistêmica. Tomamos o caso da América Latina para exemplificar, em um esforço inicial, o distanciamento da teoria de Luhmann de sua perspectiva eurocêntrica em relação à sociedade mundial, propondo corrigir sua narrativa da diferenciação funcional como fenômeno resultante de processos de transformação e evolução social internos à Europa. A correção consiste em considerar as estruturas hierárquicas supranacionais do colonialismo como parte constitutiva do processo de formação da sociedade mundial funcionalmente diferenciada.

Palavras-chave: modernidade; colonialidade; sociedade mundial; diferenciação funcional; América Latina

\section{ABSTRACT \\ Notes on Systemic Post-Colonial Sociology of Latin America}

The proximity between the epistemological and ontological assumptions in Niklas Luhmann's social theory and post-colonial approaches have been highlighted and developed throughout the last decade. However, serious doubts were raised on the possibility that Luhmann's theory of society could be disconnnected from his Eurocentric point of view. This study proposes, in general terms, a path to overcome such a deadlock in systemic theory. The example posed by the case of Latin America case should be taken into account to, initially, distance Luhmann's theory from its Eurocentric perspective with regard to world society, and later, to correct his narrative of functional differentiation as a resulting phenomenon from transformation processes and social evolution which are internal to Europe. This correction consists of considering hierarchical and supranational structures of colonialism to be constitutive parts of the formation process of a functionally differentiated world society.

Keywords: modernity; coloniality; world society; functional differentiation; Latin America 


\section{Roberto Dutra}

\section{RÉSUMÉ}

Pour une sociologie systémique post-coloniale de l'Amérique Latine

Les approximations entre les hypothèses épistémologiques et ontologiques de la théorie sociale de Niklas Luhmann et les approches postcoloniales ont été mises en évidence et développées au cours de la dernière décennie. Cependant, de sérieux doutes sont soulevés quant à la possibilité que la théorie de la société de Luhmann soit détachée de son point de vue eurocentrique. Dans cet article, nous proposons, de manière générale, comment surmonter cette impasse de la théorie systémique. On a pris le cas de l'Amérique latine pour illustrer, dans un premier effort, la distance entre la théorie de Luhmann et sa perspective eurocentrique par rapport à la société mondiale, en proposant de corriger son récit de différenciation fonctionnelle à la suite de processus de transformation et d'évolution sociale internes à l'Europe. La correction consiste à considérer les structures hiérarchiques supranationales du colonialisme comme une partie constitutive du processus de formation d'une société mondiale fonctionnellement différenciée.

Mots-clés: modernité; colonialité; société mondiale; différenciation fonctionnelle; Amérique Latine

\section{RESUMEN}

Por una Sociología Sistémica Poscolonial de América Latina

Las aproximaciones entre los presupuestos epistemológicos y ontológicos de la teoría social de Niklas Luhmann y de los abordajes poscoloniales han sido resaltadas y desarrolladas en la última década. Sin embargo, se levantan serias dudas sobre la posibilidad de que la teoría de la sociedad de Luhmann se aparte de su punto de vista eurocéntrico. En este artículo proponemos, en líneas generales, cómo se podría superar ese impase en la teoría sistémica. Tomamos el caso de América Latina para ejemplificar, en un esfuerzo inicial, el distanciamiento de la teoría de Luhmann de su perspectiva eurocéntrica en relación con la sociedad mundial, proponiendo corregir su narrativa de la diferenciación funcional como fenómeno resultante de procesos de transformación y evolución social internos a Europa. La corrección consiste en considerar las estructuras jerárquicas supranacionales del colonialismo como parte constitutiva del proceso de formación de la sociedad mundial funcionalmente diferenciada.

Palabras clave: modernidad; colonialidad; sociedad mundial; diferenciación funcional; América Latina 